Provided for non-commercial research and education use. Not for reproduction, distribution or commercial use.

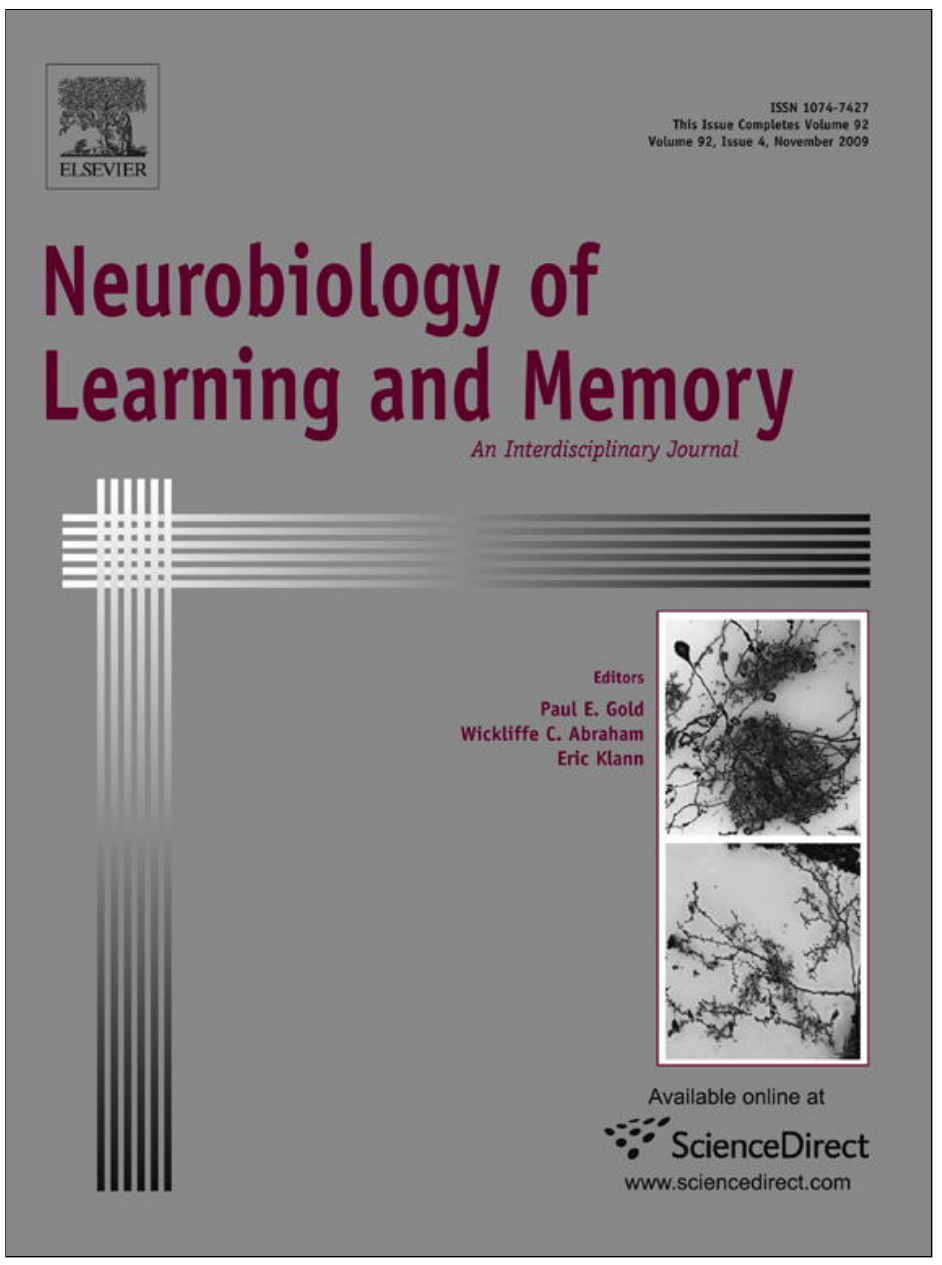

This article appeared in a journal published by Elsevier. The attached copy is furnished to the author for internal non-commercial research and education use, including for instruction at the authors institution and sharing with colleagues.

Other uses, including reproduction and distribution, or selling or licensing copies, or posting to personal, institutional or third party websites are prohibited.

In most cases authors are permitted to post their version of the article (e.g. in Word or Tex form) to their personal website or institutional repository. Authors requiring further information regarding Elsevier's archiving and manuscript policies are encouraged to visit:

http://www.elsevier.com/copyright 


\title{
Glutamate receptors in the medial geniculate nucleus are necessary for expression and extinction of conditioned fear in rats
}

\author{
Caitlin A. Orsini ${ }^{\mathrm{a}}$, Stephen Maren ${ }^{\mathrm{a}, \mathrm{b}, *}$ \\ a Department of Psychology, University of Michigan, Ann Arbor, Michigan 48109, United States \\ ${ }^{\mathrm{b}}$ Neuroscience Program, University of Michigan, Ann Arbor, Michigan 48109, United States
}

\section{A R T I C L E I N F O}

\section{Article history:}

Received 28 April 2009

Revised 14 July 2009

Accepted 21 July 2009

Available online 24 July 2009

\section{Keywords:}

Fear

Extinction

Medial geniculate nucleus

Auditory system

Glutamate

Protein synthesis

\begin{abstract}
A B S T R A C T
Auditory fear conditioning requires anatomical projections from the medial geniculate nucleus (MGN) of the thalamus to the amygdala. Several lines of work indicate that the MGN is a critical sensory relay for auditory information during conditioning, but is not itself involved in the encoding of long-term fear memories. In the present experiments, we examined whether the MGN plays a similar role in the extinction of conditioned fear. Twenty-four hours after Pavlovian fear conditioning, rats received bilateral intrathalamic infusions of either with NBQX (an AMPA receptor antagonist; Experiment 1) or MK-801 (an NMDA receptor antagonist; Experiment 1), anisomycin (a protein synthesis inhibitor; Experiment 2) or U0126 (a MEK inhibitor; Experiment 3) immediately prior to an extinction session in a novel context. The next day rats received a tone test in a drug-free state to assess their extinction memory; freezing served as an index of fear. Glutamate receptor antagonism prevented both the expression and extinction of conditioned fear. In contrast, neither anisomycin nor U0126 affected extinction. These results suggest that the MGN is a critical sensory relay for auditory information during extinction training, but is not itself a site of plasticity underlying the formation of the extinction memory.
\end{abstract}

(c) 2009 Elsevier Inc. All rights reserved.

\section{Introduction}

Auditory fear conditioning is an essential behavioral paradigm used to understand the neural circuits involved in fear learning and memory. During this behavioral procedure, an acoustic tone (conditioned stimulus; CS) is paired with an aversive footshock (unconditioned stimulus; US) (Maren, 2001). After several trials, animals begin to manifest conditioned responses (CRs), such as increases in heart rate and freezing, indicating learned fear (Fanselow \& Poulos, 2005; Maren, 2001). If, however, the CS is repeatedly presented alone, animals learn that the tone no longer predicts the occurrence of the US and consequently suppress fear to the CS (Quirk \& Mueller, 2008). This decrease in fear with CSalone presentations is known as extinction and is considered a form of new inhibitory learning rather than the erasure of the fear memory.

It is well established that the amygdala is critical for both fear conditioning and extinction (Corcoran \& Quirk, 2007; Maren \& Quirk, 2004; Myers \& Davis, 2002). Furthermore, it is apparent that the acquisition and retrieval of extinction memories requires the hippocampus and prefrontal cortex (Ji \& Maren, 2007; Maren \&

\footnotetext{
* Corresponding author. Address: Department of Psychology, University of Michigan, 530 Church Street, Ann Arbor, MI 48109-1043, United States. Fax: +1 7347637480

E-mail address: maran@umich.edu (S. Maren).
}

Quirk, 2004). However, although much is known about the telencephalic structures involved in extinction, it is not known how upstream sensory afferents of the forebrain contribute to extinction learning. For auditory fear conditioning, the medial geniculate nucleus (MGN) is essential (Iwata, LeDoux, Meeley, Arneric, \& Reis, 1986; LeDoux, Iwata, Pearl, \& Reis, 1986; LeDoux, Ruggiero, \& Reis, 1985; LeDoux, Sakaguchi, \& Reis, 1983). Lesions of the MGN prior to auditory fear conditioning prevent the acquisition of fear as assessed by freezing and other measures of aversive learning (Jarrell, Gentile, McCabe, \& Schneiderman, 1986; LeDoux et al., 1983; McCabe, McEchron, Green, \& Schneiderman, 1993). Additionally, associative plasticity in the MGN is associated with conditioning and extinction (Edeline \& Weinberger, 1992; Lennartz \& Weinberger, 1992; McEchron, McCabe, Green, Llabre, \& Schneiderman, 1995). Pharmacological blockade of protein synthesis in the MGN has also been shown to prevent the formation of fear memory (Parsons, Riedner, Gafford, \& Helmstetter, 2006; cf. Aspergis-Schoute, Debiec, Doyere, LeDoux, \& Schafe, 2005; Maren, Ferrario, Corcoran, Desmond, \& Frey, 2003). Taken together, lesion, electrophysiological and pharmacological studies indicate that the MGN is necessary for auditory fear conditioning.

While there is a plethora of research demonstrating the role of the MGN in auditory fear conditioning, its involvement in extinction is less clear. Heldt and Falls (2006) found that extensive lesions of the medial geniculate body that included the posterior intralaminar nucleus (PIN) impaired the ability of a noise to inhibit 
conditional responding to a light CS. This form of conditioned inhibition may have some parallels with extinction. However, infusions of an NMDA antagonist did not affect latent inhibition (Schauz \& Koch, 2000), another learning process with similarities to extinction (Bouton, 1993). Hence, the role of the MGN in inhibitory learning is unclear.

The purpose of the current experiments was to elucidate the contribution of the MGN in the acquisition of extinction. To this end, we used pharmacological manipulations to block NMDA and AMPA receptors in the MGN. Excitatory synaptic transmission was targeted because previous literature has shown that antagonizing AMPA and NMDA receptors in the MGN prevents unit responses when the inferior colliculus is stimulated (Webber, Green, Winters, Schneiderman, \& McCabe, 1997). We also assessed whether signaling cascades downstream of glutamate receptors are involved in extinction memory. In Experiments 2 and 3, we examined whether intra-MGN infusions of anisomycin, a protein synthesis inhibitor, or U0126, a mitogen-activated protein kinase (MEK) inhibitor, influences extinction. Our hypothesis was that inhibiting excitatory synaptic transmission in the MGN with glutamate antagonists would both prevent the expression of fear to an auditory cue during extinction training and reduce the acquisition of the extinction learning.

\section{General materials and methods}

\subsection{Subjects}

The subjects in all experiments were male Long-Evans rats (220-224 g; Blue Spruce) obtained from a commercial provider (Harlan Sprague-Dawley, Indianapolis, IN). Upon arrival, the animals were individually housed in clear plastic hanging cages in a stainless steel rack. Animals were kept on a 14:10 light:dark cycle and had free access to food and water. All rats were handled for $15-20 \mathrm{~s}$ per day for five consecutive days after initial housing to acclimate them to the researcher. All experimental procedures were carried out in accordance with the protocols approved by the University of Michigan University Committee on Use and Care of Animals.

\subsection{Behavioral apparatus}

Training and testing procedures were conducted in eight identical conditioning chambers $(30 \times 24 \times 21 \mathrm{~cm}$; Med-Associates, St. Albans, VT) in sound-attenuating cabinets. The conditioning chambers consisted of two aluminum walls and a Plexiglas back, ceiling and door. To deliver the footshock, each chamber's floor had 19 stainless steel rods, which were wired to a shock source and a solid-state grid scrambler (Med-Associates, St. Albans, VT). In addition, each chamber contained ventilation fans and house lights, both of which were manipulated to create different contexts during training, extinction and testing. For context A (used for conditioning), the ventilation fans were turned on (65 dB), house lights and room lights were on, the cabinet doors were open and the chambers were cleaned with $1 \%$ acetic acid. For context B (used during extinction and the test session), the room was illuminated by fluorescent red lights, the ventilation fans and chamber lights were turned off, the cabinet doors were closed and the chambers were cleaned with $1 \%$ ammonium hydroxide. Stainless steel pans rinsed with the respective cleaner for each context were placed below the floor grids in the chambers prior to placing the animals in the chambers.

Motor activity of the animals was measured by recording the displacement of each chamber via a load cell platform underneath each chamber. Each load cell amplifier was calibrated prior to the start of the experiment to a fixed chamber displacement, and the output of each amplifier was set to a level that optimally detected freezing behavior. All output was recorded using Threshold Activity software (Med-Associates).

\subsection{Surgery}

Rats were anesthetized with sodium pentobarbital $(65 \mathrm{mg} / \mathrm{kg}$ body weight, i.p.) and given atropine sulfate $(0.4 \mathrm{mg} / \mathrm{kg}$ body weight, i.p.) prior to being mounted on a stereotaxic apparatus (David Kopf instruments). The scalp was incised and retracted and the head was positioned to place bregma and lambda in the same horizontal plane. Burr holes were drilled for the bilateral implantation of 26-gauge guide cannula (Plastics One) into the MGN ( $-6.0 \mathrm{~mm}$ AP from bregma; $\pm 3.1 \mathrm{~mm}$ ML from midline; -5.5 DV from dura). Three additional holes were drilled for small jeweler's screws placed both anterior and posterior to the guide cannula. Dental acrylic was applied around the guide cannulas and screws to affix the cannula to the skull. Dummy cannulas (33-gauge; $11 \mathrm{~mm}$; Plastics One) were inserted into the guide cannulas to prevent clogging. Rats recovered on a heating pad prior to being returned to their home cages. All animals were allowed 7 days post-operative care, including daily dummy cannula changes, before behavioral testing commenced.

\subsection{Procedure}

Prior to conditioning, all animals were acclimated to the infusion procedure by placing them in buckets filled with bedding, removing dummies and running the infusion pumps (Harvard apparatus) for $3 \mathrm{~min}$. For conditioning, animals were transported in squads of eight to the conditioning chambers for the initial training session in context $A$. The chamber position for the animals was counterbalanced across each squad and experimental group. Rats received 5 tone $(85 \mathrm{~dB}, 10 \mathrm{~s}, 2 \mathrm{kHz})$-footshock $(1.0 \mathrm{~mA}, 2.0 \mathrm{~s})$ pairings with a 60-s intertrial interval and were removed from the chambers one minute after the final shock. Twenty-four hours later, animals were placed in the infusion buckets and transported to the infusion room. Hamilton syringes $(10 \mu \mathrm{l})$ were placed on an infusion pump and connected to injection needles with polyethylene tubing. After infusion of the drugs, the injectors remained in the guide cannula for one minute after infusion to allow for diffusion of the drug or vehicle. Clean dummy cannulas were inserted into the guide cannulas and animals were immediately transported to context B for an extinction session. The extinction session consisted of 45 tone- $(85 \mathrm{~dB}, 10 \mathrm{~s}, 2 \mathrm{kHz})$ alone trials that began three minutes after rats were placed in the chambers and ended 3 min after the last tone with an intertrial interval (ITI) of $60 \mathrm{~s}$ (Experiment 1a) or 30 s (Experiments 1b, 2 and 3). A control group was infused with vehicle and placed in the chambers but did not receive tone presentations, serving as a no-extinction control. Twenty-four hours after extinction, all squads were transported back to the conditioning chambers in context $B$ for a drug-free test (45 tone $(85 \mathrm{~dB}, 10 \mathrm{~s}, 2 \mathrm{kHz})$ alone trials with an ITI of $60 \mathrm{~s}$ (Experiment 1a) or $30 \mathrm{~s}$ (Experiments $1 \mathrm{~b}, 2$ and 3 ). Freezing (somatomotor immobility) was used as an index of fear throughout all behavioral sessions.

After behavioral testing, animals were perfused across the heart with $0.9 \%$ saline followed by $10 \%$ formalin. Brains were extracted and preserved in $10 \%$ formalin for 2 days before being transferred into $30 \%$ sucrose formalin. Brains were sectioned $(45 \mu \mathrm{m})$ on a cryostat maintained at $-20^{\circ} \mathrm{C}$. All sections were wet mounted on microscope slides with $70 \%$ ethanol and were subsequently stained with $0.25 \%$ thionin to verify cannula placements. 


\subsection{Data analysis}

Output from the load cells was converted into freezing scores for statistical analyses, which consisted of repeated measures ANOVA followed by Fisher's PLSD post-hoc comparisons. All data are represented by means \pm SEM.

\section{Experiment 1a: glutamate antagonism in the MGN during extinction}

Ninety-one animals received bilateral MGN infusions of either 2,3-dihydroxy-6-nitro-7-sulfamoyl-benzo[f]quinoxaline-2,3-dione (NBQX), (+)-5-methyl-10,11-dihydro-5H-dibenzo[a,d]cyclohepten-5,10-imine maleate (MK-801), a combination of both NBQX and MK-801 or vehicle (0.1 M phosphate-buffered solution (PBS)) at a rate of $0.1 \mu \mathrm{l} / \mathrm{min}$ for a total of $3 \mathrm{~min}(0.3 \mu \mathrm{l}$ total infused volume). NBQX ( $3 \mu \mathrm{g}$ at a concentration of $10 \mu \mathrm{g} / \mu \mathrm{l}$ at $\mathrm{pH}$ 7.4; Sigma) was dissolved in 0.1 M PBS and MK-801 (3.75 $\mu \mathrm{g}$ at a concentration of $12.5 \mathrm{mg} / \mathrm{ml}$; Sigma) was dissolved in $20 \%$ DMSO in $0.9 \%$ saline. For the cocktail of the two drugs, MK-801 (3.75 $\mu \mathrm{g}$ at a concentration of $12.5 \mathrm{mg} / \mathrm{ml}$ in $20 \%$ DMSO) was combined $1: 1$ with NBQX ( $3.0 \mu \mathrm{g}$ at a concentration of $10 \mu \mathrm{g} / \mu \mathrm{l}$ in $0.1 \mathrm{M} \mathrm{PBS}$ ). Serving as a control, vehicle (0.1 M PBS, $20 \%$ DMSO, or a combination of the two) was infused as well. Thus, there were five groups in the paradigm: three drug-extinction groups (COMB-E, NBQX-E, MK-E), a vehicle-extinction group (VEH-E) and a vehicle-no extinction group (VEH-NE). The dose of NBQX used in this study is effective at impairing fear-potentiated startle when infused into the amygdala (Walker \& Davis, 1997) and the dose of MK-801 has been reported to block fear conditioning when infused into the hippocampus (Zhang, Bast, \& Feldon, 2001).

\section{Experiment 1b: glutamate antagonism in the MGN during a short extinction session}

Seventy-nine animals received bilateral MGN infusions of either NBQX, MK-801, a combination of both NBQX and MK-801 or vehicle at a rate of $0.1 \mu \mathrm{l} / \mathrm{min}$ for a total of $3 \mathrm{~min}$, as previously described. Behavioral procedures differed only in that the ITI in the extinction session was $30 \mathrm{~s}$, thus shortening the overall duration of session.

\section{Experiment 2: post-extinction inhibition of protein synthesis in the MGN with anisomycin}

Thirty animals received bilateral infusions of anisomycin (37.5 $\mu \mathrm{g}$ at a concentration of $125 \mu \mathrm{g} / \mu \mathrm{l}$; Sigma) or vehicle (artificial cerebrospinal fluid; ACSF) into the MGN $(0.3 \mu \mathrm{l} ; 0.1 \mu \mathrm{l} / \mathrm{min}$ for $3 \mathrm{~min}$ ). This dose of anisomycin is effective in blocking the consolidation of auditory fear memories when infused into the MGN (Parsons et al., 2006) or amygdala (Maren et al., 2003). Anisomycin was dissolved in hydrochloric acid $(\mathrm{HCl} ; 1.0 \mathrm{M})$ and subsequently diluted with ACSF. A small quantity of sodium hydroxide $(\mathrm{NaOH}$; $1.0 \mathrm{M}$ ) was added so as to obtain a $\mathrm{pH}$ of 7.2. Animals were returned to the home cages for $30 \mathrm{~min}$ post-infusion before being placed in the conditioning chambers for extinction before testing, as was done by Parsons and colleagues (2006).

\section{Experiment 3: inhibition of ERK in the MGN during extinction}

Thirty-six animals received bilateral infusions of U0126, a MEK inhibitor $(1.0 \mu \mathrm{g}$ at a concentration of $3.33 \mu \mathrm{g} / \mu \mathrm{l}$; Promega) into the MGN $(0.3 \mu \mathrm{l} ; 0.1 \mu \mathrm{l} / \mathrm{min}$ for $3 \mathrm{~min})$. This dose of U0126 is effective at impairing long-term retention of auditory fear memories when infused into the MGN (Aspergis-Schoute et al., 2005). The drug was first dissolved in 100\% DMSO and then diluted with ACSF 50:50. Another group of animals received infusions of vehicle (combination of ACSF and DMSO 50:50) into the MGN prior to extinction. Rats were returned to their home cages for $30 \mathrm{~min}$ prior to being placed into conditioning chambers for extinction, similar to the procedure reported by Aspergis-Schoute et al. (2005).

\section{Results}

\subsection{Experiment 1a: glutamate antagonism in the MGN during extinction}

Temporary inactivation or lesions of the MGN prior to auditory fear conditioning disrupts the formation of fear memories (Iwata et al., 1986; LeDoux et al., 1983, 1985; Maren et al., 2003). However, the involvement of the MGN in extinction is not known. In this experiment, NBQX, MK-801, or a cocktail of the two compounds was infused bilaterally into the MGN prior to extinction. Short-term fear responses were measured during the auditory fear conditioning procedure; long-term fear responses were assessed again in a novel context during an extinction session and a tone test session on days 2 and 3, respectively.

\subsubsection{Histology}

Cannula placements for each experiment are shown in Fig. 1. The cannula tips were centered on the medial geniculate body, including the posterior intralaminar nucleus (PIN), the medial division of the medial geniculate nucleus (MGm) and the ventral division of the medial geniculate nucleus (MGv). Nineteen rats were excluded from the analyses of due to inaccurate cannula placements. These exclusions yielded the following group sizes: NBQX-E $(n=14)$, MK-E $(n=14)$, COMB-E $(n=15)$, VEH-E $(n=23)$ and VEH-NE $(n=25)$.

\subsubsection{Behavior}

Freezing behavior for the conditioning, extinction and test sessions is displayed in Fig. 2A-C. During the pretrial period of the training session, animals did not freeze prior to the first tone-shock presentation. Freezing behavior gradually increased over the five conditioning trials until it reached an asymptote (Fig. 2A). There were no significant differences between groups, $\left(F_{(4,86)}=0.11\right.$, $p=0.98)$. During extinction, all animals showed low levels of freezing during the pretrial period. During the first tone presentation, VEH-E animals displayed high levels of fear during the ITI that gradually declined over the course of the extinction session. However, both the VEH-NE and drug (COMB-E, MK-E and NBQX-E) groups displayed very little freezing throughout the entire extinction session. There was a significant main effect across the session $\left(F_{(4,86)}=8.14, p<0.001\right.$; Fig. $\left.2 \mathrm{~B}\right)$ and subsequent post-hoc tests revealed that animals that received drug were significantly different than the VEH-E group $(p<0.005)$. Additionally, the drug groups were not significantly different than the VEH-NE group (NBQX-E and VEH-NE, $p=0.99$; MK-E and VEH-NE, $p=0.11$; COMB-E and VEH-NE, $p=0.37$ ).

During the test session $24 \mathrm{~h}$ later, the VEH-E animals expressed significantly lower levels of freezing than VEH-NE animals, indicating that they had extinguished their fear to the CS. The drug groups also displayed low levels of freezing, suggesting that they too underwent extinction. There was a statistically significant main effect due to the manipulation the previous day, $\left(F_{(4,86)}=5.41\right.$, $p<0.05$; Fig. 3c). Post-hoc analyses did not reveal a reliable difference between the drug groups and the VEH-E group (NBQX-E and VEH-E, $p=0.92$; MK-E and VEH-E, $p=0.71$; COMB-E and VEH-E, $p=0.33$ ). To assess levels of fear independent of additional extinction during the test session, further analyses focused on the first 15 

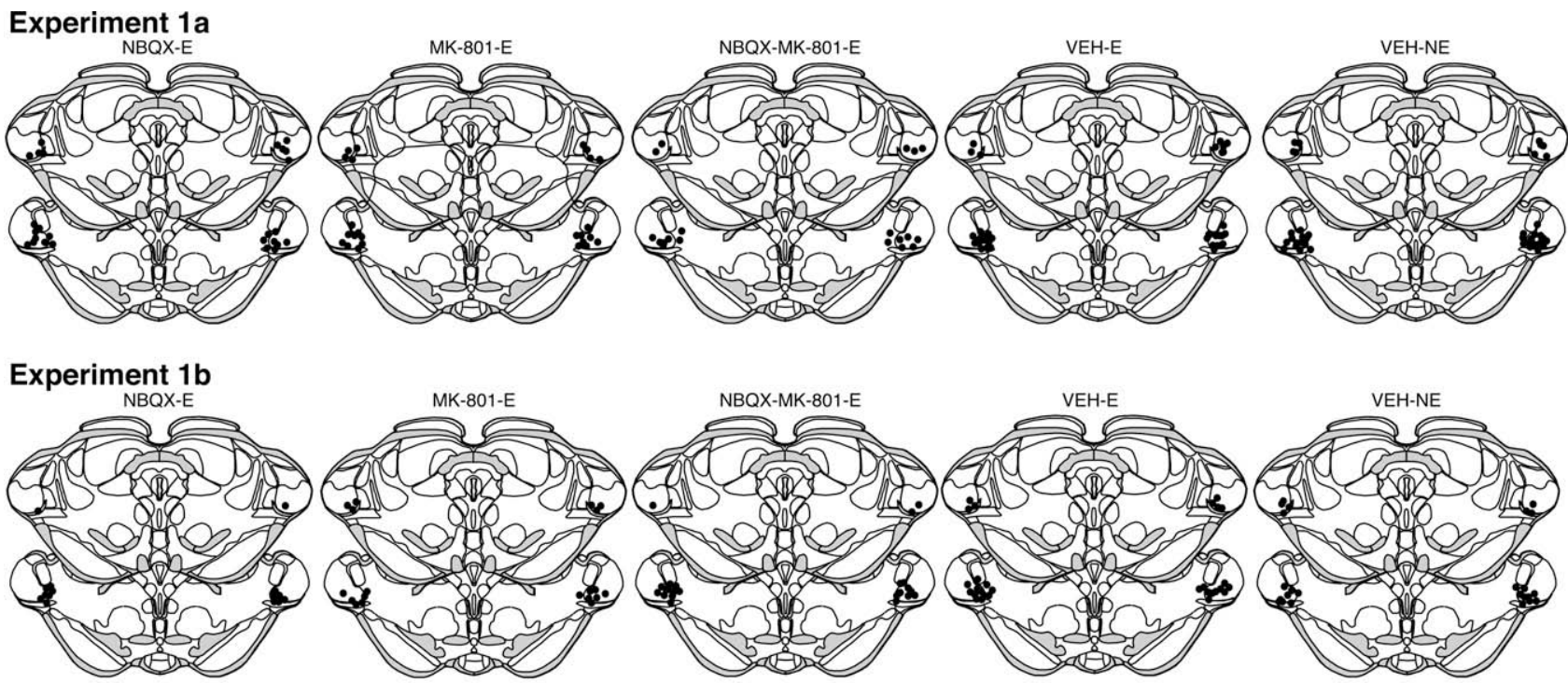

\section{Experiment 2}
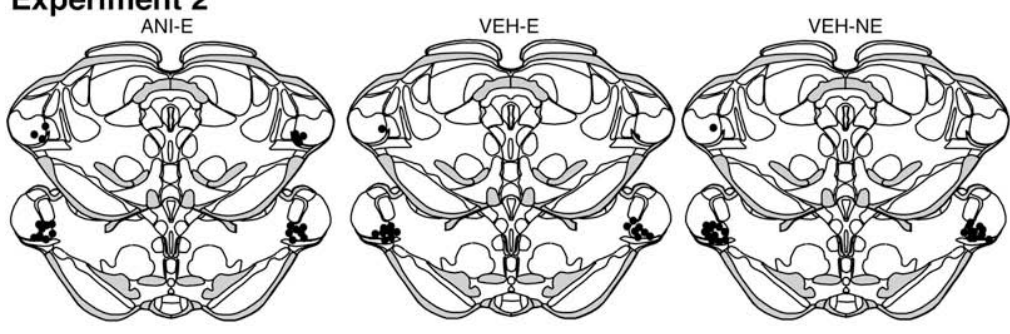

\section{Experiment 3}
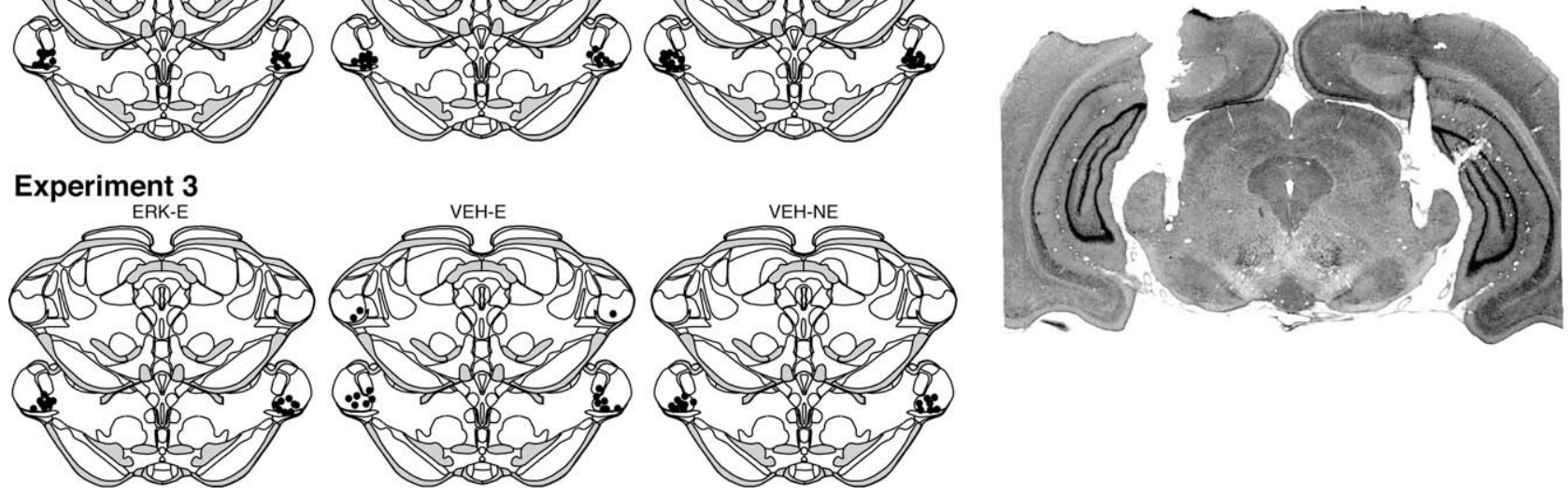

Fig. 1. Schematic illustration of cannula placements in Experiments 1a, 1b, 2 and 3. Each pair of coronal brain sections displays the cannula placements in each group of rats The filled black circles represent the location of the tips of the guide cannula. A photomicrograph of a representative coronal section stained with thionin illustrates a bilateral cannula implant in the MGN. Coronal brain sections were adapted from Swanson (2004).
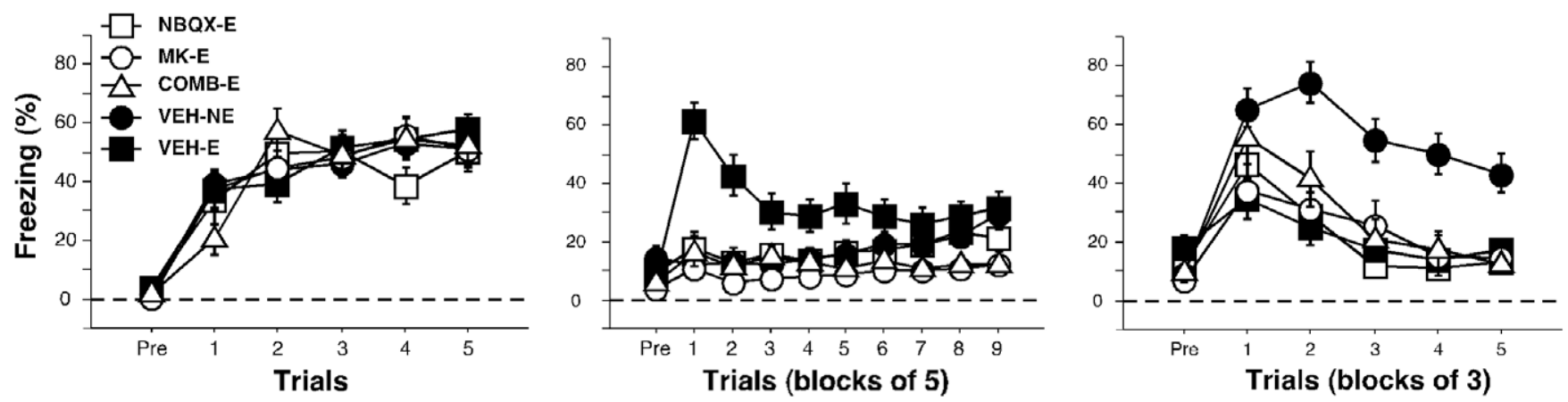

Fig. 2. Conditioned freezing in rats receiving intra-thalamic infusions of glutamate receptor antagonists prior to extinction (Experiment 1a). (A) Mean percentage of freezing ( \pm SEM) during training that consisted of a pretrial period (Pre) followed by 5 tone-shock presentations. Freezing was measured during the pretrial period and the 1 min intertrial interval. (B) Mean percentage of freezing ( \pm SEM) during the 45 tone-alone extinction session (data are displayed in 15 bins consisting of 3 trials averaged together). (C) Mean percentage of freezing ( \pm SEM) during the first $15 \mathrm{~min}$ of the 45 tone-alone tone test (data are displayed in 5 bins of 3 trials averaged together). Data is shown for rats that were extinguished under NBQX (open squares), MK-801 (open circles), NBQX and MK-801 (open triangles) or vehicle (filled squares). Data for animals that were not extinguished under vehicle are also shown (filled circles). 

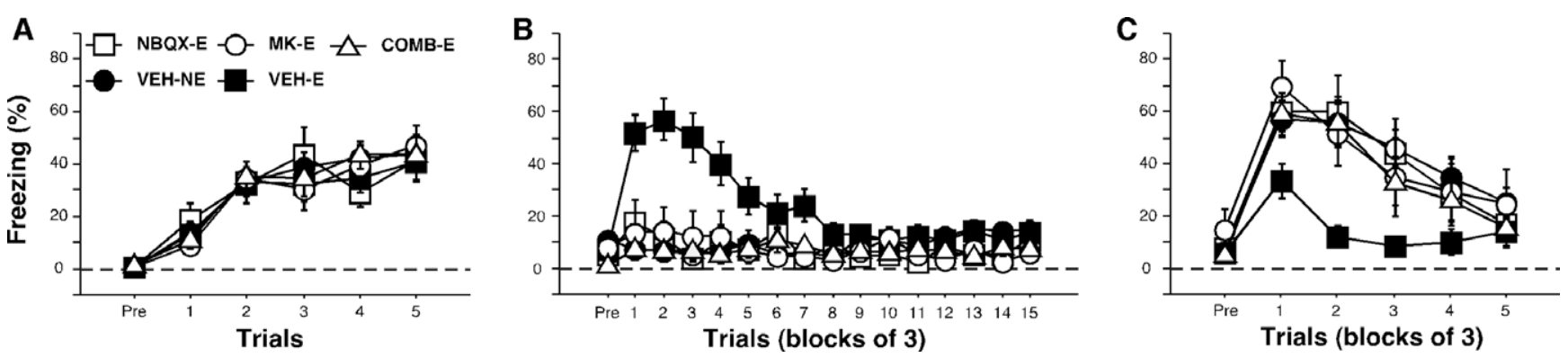

Fig. 3. Conditioned freezing in rats receiving intra-thalamic infusions of glutamate receptor antagonists prior to an abbreviated extinction session (Experiment $1 \mathrm{~b})$. (A) Mean percentage of freezing $( \pm$ SEM) during training that consisted of a pretrial period (Pre) followed by 5 tone-shock presentations. Freezing was measured during the pretrial period and the $1 \mathrm{~min}$ intertrial interval. (B) Mean percentage of freezing ( \pm SEM) during the 45 tone-alone extinction session (data are displayed in 15 bins consisting of 3 trials averaged together). Freezing was measured during the pretrial period and the 30 s intertrial intervals. (C) Mean percentage of freezing ( \pm SEM) during the first 15 min of the 45 tone-alone tone test (data are displayed in 5 bins of 3 trials averaged together). Data is shown for rats that were extinguished under NBQX (open squares), MK-801 (open circles), NBQX and MK-801 (open triangles) or vehicle (filled squares). Data for animals that were not extinguished under vehicle are also shown (filled circles).

trials of the tone test. This analysis yielded a statistically significant main effect due to the manipulation the previous day, $\left(F_{(4,86)}=8.81, p<0.01\right.$; Fig. $\left.2 \mathrm{C}\right)$. Though post-hoc analyses did not reveal significant differences between the experimental groups, there was a trend towards a significant difference between the COMB-E group and the VEH-E during the first $5 \mathrm{~min}$ of the session. These results suggest a weak effect of the combination of NMDA and AMPA receptor antagonists on extinction.

\subsection{Experiment $1 b$ : glutamate antagonism in the MGN during $a$ shortened extinction session}

Because there was a trend for an effect of NBQX and MK-801 on extinction, Experiment 1b was conducted to further explore this effect. Because the extinction session in Experiment 1a may have been longer ( $57 \mathrm{~min} 30 \mathrm{~s}$ ) than the effective duration of the drugs, the extinction session in Experiment $1 \mathrm{~b}$ was reduced to $35 \mathrm{~min}$ and $30 \mathrm{~s}$ by halving the intertrial interval. We expected that under these conditions glutamate receptor antagonists would interfere with extinction.

\subsubsection{Histology}

Cannula placements are shown in Fig. 1. Twenty-three animals were excluded due to inaccurate cannula placements or illness during the experiment. One VEH-E animal was a statistical outlier during the tone test as indicated by the Grubb's test $(p<0.05)$ and was thus excluded from analyses. These exclusions resulted in the following group sizes: NBQX-E $(n=8)$, MK-E $(n=8)$, COMB-E $(n=17)$, VEH-E $(n=20)$ and VEH-NE $(n=26)$.

\subsubsection{Behavior}

Freezing behavior for conditioning, extinction and test session are displayed in Fig. 3A-C. During the pretrial period of the training session, the animals did not freeze. Freezing behavior gradually increased until it reached an asymptote (Fig. $3 \mathrm{~A}$ ). There were no significant differences between groups, $\left(F_{(4,75)}=0.33, p=0.86\right)$. During extinction, there were low levels of freezing during the pretrial period; however, with the first tone-alone presentation, the VEH-E animals exhibited high levels of freezing, expressing the fear that was acquired the day before. Levels of freezing gradually declined within the session. Both VEH-NE and drug animals displayed low levels of freezing throughout the entire extinction session. Indeed, there was a significant main effect, $\left(F_{(4,75)}=8.63, p<0.001\right.$; Fig. 3B) and post-hoc analyses revealed that VEH-NE animals and drug groups did not differ (NBQX-E and VEH-NE, $p=0.76$; MK-E and VEH-NE, $p=0.72$; COMB-E and VEH-NE, $p=0.52$ ) whereas the VEH-NE and drug groups were statistically different than the VEH-E animals $(p<0.005)$.
During the tone test $24 \mathrm{~h}$ later, low levels of freezing were observed during the pretrial period in all groups (Fig. 3C). After the delivery of test trials, the VEH-E group showed low levels of fear whereas the drug groups and the VEH-NE froze significantly more. Nonetheless, there was not a significant effect during the tone test session, $\left(F_{(4,75)}=2.10, p=0.09\right)$. As in Experiment $1 \mathrm{a}$, further analyses focused on the first 15 trials to isolate levels of fear independent of additional extinction. This analysis confirmed a significant difference between groups $\left(F_{(4,75)}=3.38, p<0.05\right)$, and post-hoc analyses revealed that the drug groups and VEH-NE group were statistically different than the VEH-E group $(p<0.05)$. However, the VEH-NE group and the drug groups exhibited statistically similar levels of freezing (NBQX-E and VEH-NE, $p=0.85$; MK-E and VEH-NE, $p=0.85$; COMB-E and VEH-E, $p=0.47$ ). These results suggest that the glutamate receptor antagonism in the MGN prevented extinction.

\subsection{Experiment 2: inhibition of protein synthesis in the MGN with anisomycin}

Although Experiment 1b indicates that glutamate receptors in the MGN are required for extinction to an auditory cue, it is not clear whether their participation contributes to the formation of extinction memories or whether they are merely responsible for transmitting sensory information to the amygdala. If the former were true, one would expect that extinction would be impaired by protein synthesis inhibition in the MGN. For example, the consolidation of fear conditioning is disrupted by protein synthesis inhibitors in the amygdala (Maren et al., 2003; Schafe \& LeDoux, 2000) or the MGN (Parsons et al., 2006; but see Aspergis-Schoute et al., 2005; Maren et al., 2003). Thus, to delineate the specific role of glutamate receptors in the MGN during extinction, anisomycin, a protein synthesis inhibitor, was infused bilaterally in the MGN prior to extinction.

\subsubsection{Histology}

Cannula placements are shown in Fig. 1. Six rats were excluded from the analyses due to inaccurate cannula placements. This exclusion resulted in the following group sizes: ANI-E $(n=11)$, VEH-E $(n=8)$ and VEH-NE $(n=11)$.

\subsubsection{Behavior}

Freezing behavior during the conditioning, extinction and test sessions is displayed in Fig. 4A-C. During the pretrial period of the training session, animals did not freeze. After the delivery of conditioning trials, freezing behavior gradually increased until it reached an asymptote (Fig. $4 \mathrm{~A}$ ). There were no significant differences between groups during the training session, $\left(F_{(2,24)}=0.29\right.$, 

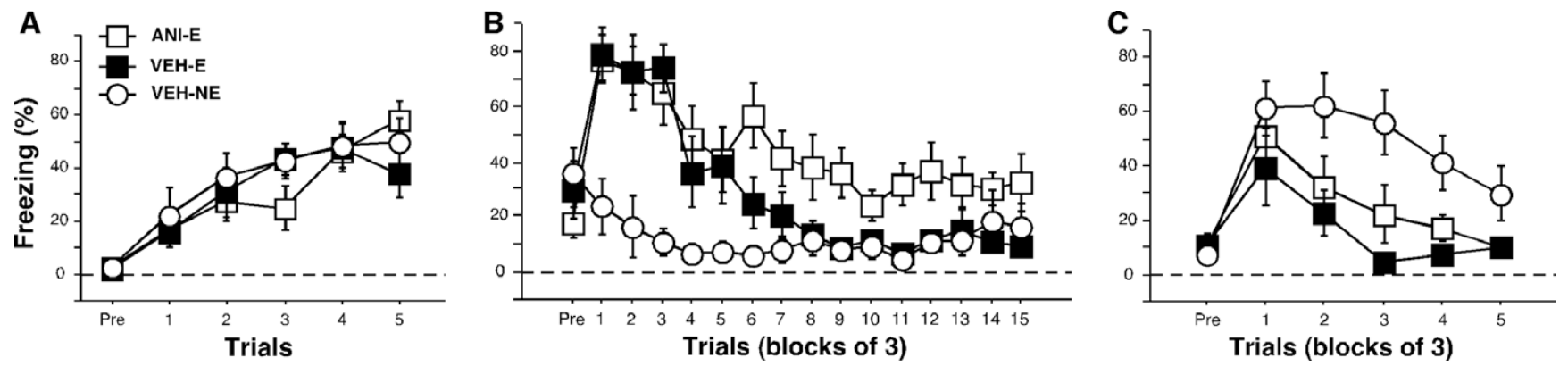

Fig. 4. Conditioned freezing in rats receiving intra-thalamic infusions of a protein synthesis inhibitor prior to extinction (Experiment 2). (A) Mean percentage of freezing $( \pm \mathrm{SEM})$ during training that consisted of a pretrial period (Pre) followed by 5 tone-shock presentations. Freezing was measured during the pretrial period and the 1 min intertrial interval. (B) Mean percentage of freezing ( \pm SEM) during the 45 tone-alone extinction session (data are displayed in 15 bins consisting of 3 trials averaged together). Freezing was quantified during the pretrial period and the $30 \mathrm{~s}$ intertrial intervals. (C) Mean percentage of freezing ( \pm SEM) during the first 15 min of the 45 tone-alone tone test (data are displayed in 5 bins of 3 trials averaged together). Data is shown for rats that were extinguished under anisomycin (open squares) or vehicle (filled squares). Data for animals that were not extinguished under vehicle are also shown (open circles).

$p=0.75$ ). During the extinction session, low levels of freezing were observed in the pretrial period of the extinction session. After the first CS onset, the VEH-E group and ANI-E groups exhibited high levels of freezing, expressing the fear acquired the previous day. Freezing levels in these groups gradually declined over the session. The VEH-NE group, however, displayed low levels of freezing throughout the entire extinction session. A significant main effect was observed during the extinction session, $\left(F_{(2,24)}=9.23\right.$, $p<0.05$; Fig. 4B). Post-hoc analysis revealed that both the ANI-E and VEH-E groups were statistically different than the animals in the VEH-NE group $(p<0.05)$. Additionally, there was a trend towards significance between the ANI-E and VEH-E groups. ANI-E and VEH-E groups were analyzed separately using a repeated measures ANOVA with group and trial block as independent variables. Based on this analysis, there was no significant difference between the ANI-E and VEH-E groups $\left(F_{(1,16)}=3.88 ; p=0.07\right)$, and no significant interaction between group and trial block $\left(F_{(1,14)}=1.38\right.$; $p=0.16$ ), indicating similar rates of extinction in both groups.

During the test session $24 \mathrm{~h}$ later, all groups expressed low levels of fear during the pretrial period. Throughout the tone test, the ANI-E and VEH-E groups displayed low levels of freezing, indicating successful extinction. The VEH-NE group initially displayed high levels of freezing, but these levels declined throughout the session. There was not a significant effect of the drug manipulation the day before, $\left(F_{(2,24)}=2.42, p=0.28\right)$. However, an analysis of the first $15 \mathrm{~min}$ of the test session revealed a significant group effect, $\left(F_{(2,24)}=6.41, p<0.05\right.$; Fig. $\left.4 \mathrm{C}\right)$. Post-hoc analyses revealed that the VEH-NE group was significantly different than both the ANI-E and VEH-E groups $(p<0.05)$, which did not differ from one an- other. The results reveal that protein synthesis inhibition in the MGN does not affect the retention of extinction.

\subsection{Experiment 3: inhibition of ERK in the MGN}

Although Experiment 2 indicates that protein synthesis in the MGN is not involved in the formation of extinction memory, other studies have indicated that ERK/MAPK in the MGN may be involved encoding fear memory despite minimal effects of protein synthesis inhibition (Aspergis-Schoute et al., 2005). Specifically, it has been shown that infusions of U0126, a MEK inhibitor (which normally phosphorylates ERK), impair auditory fear conditioning whereas the infusions of anisomycin do not (Aspergis-Schoute et al., 2005). Thus, it is possible that blocking downstream intracellular processes, but not general protein synthesis, could interrupt the formation of extinction memories. To investigate whether ERK in the MGN plays a role in extinction, we infused U0126 into the MGN prior to extinction.

\subsubsection{Histology}

Cannula placements are shown in Fig. 1. Nine animals were excluded due to inaccurate cannula placements. Additionally, two rats were excluded as they became sick during the experiment. Thus, these exclusions yielded the following group sizes: ERK-E $(n=8)$, VEH-E $(n=8)$ and VEH-NE $(n=9)$.

\subsubsection{Behavior}

Freezing behavior from the conditioning, extinction and the test sessions is shown in Fig. 5A-C. During the pretrial period of the
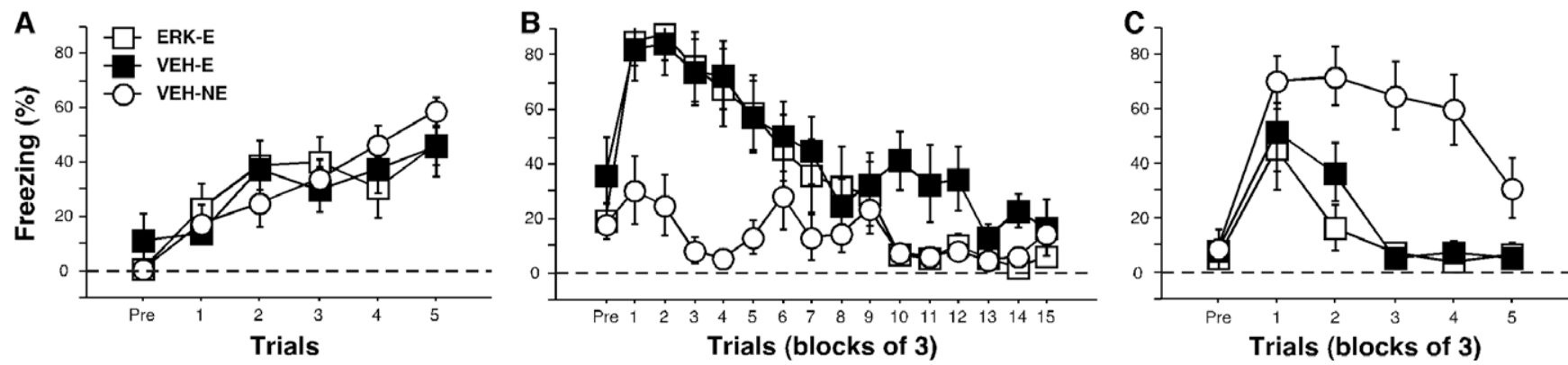

Fig. 5. Conditioned freezing in rats receiving intra-thalamic infusions of a MEK inhibitor prior to extinction (Experiment 3 ). (A) Mean percentage of freezing ( \pm SEM) during training that consisted of a pretrial period (Pre) followed by 5 tone-shock presentations. Freezing was measured during the pretrial period and the 1 min intertrial interval. (B) Mean percentage of freezing $( \pm$ SEM) during the 45 tone-alone extinction session (data are displayed in 15 bins consisting of 3 trials averaged together). Freezing was quantified during the pretrial period and the $30 \mathrm{~s}$ intertrial interval. (C) Mean percentage of freezing ( \pm SEM) during the first 15 min of the 45 tone-alone tone test (data are displayed in 5 bins of 3 trials averaged together). Data is shown for rats that were extinguished under U0126 (open squares) or vehicle (filled squares). Data for animals that were not extinguished under vehicle are also shown (open circles). 
training session, the animals did not freeze. Freezing behavior gradually increased with each tone-shock presentation until it reached an asymptote (Fig. 5A). There were no significant differences between experimental groups, $\left(F_{(2,21)}=0.15, p=0.86\right)$. During the extinction session, animals showed low levels of freezing during the pretrial period. Both VEH-E and ERK-E groups initially exhibited high levels of freezing during the first few tone presentations, but levels gradually declined throughout the session. The VEH-NE animals expressed low levels of fear during the entire extinction period. There was a significant main effect during the tone presentations within the session, $\left(F_{(2,21)}=6.61, p<0.05\right.$; Fig. 5B) and post-hoc analyses revealed significant differences between the VEH-E and VEH-NE group as well as the ERK-E group and the VEH-NE group $(p<0.05)$.

When tested $24 \mathrm{~h}$ later, there were low levels of freezing during the pretrial period in all groups (Fig. 5C). Animals in the ERK-E group or the VEH-E group expressed low levels of fear during the tone test, indicating successful extinction of fear to the auditory CS. The VEH-NE group, however, displayed high levels of freezing behavior at the outset of the session, which gradually decreased throughout the session $\left(F_{(2,21)}=6.30, p<0.05\right.$; Fig. 5C). Post-hoc analyses revealed that both VEH-E and ERK-E groups were significantly different than the VEH-NE group $(p<0.05)$. Using a similar analysis of the first 15 trials of the session as performed in the previous experiments, a significant main effect of group was observed, $\left(F_{(2,21)}=11.9, p<0.05\right.$; Fig. $\left.5 \mathrm{C}\right)$. Post-hoc analyses revealed that both VEH-E and ERK-E groups were significantly different than the VEH-NE group $(p<0.05)$.

\section{Discussion}

The present experiments aimed to determine the role of glutamate receptors and downstream molecular cascades in the MGN in the extinction of conditioned fear. We found that both AMPA and NMDA antagonism in the MGN prevented expression of fear to an auditory CS (Experiments $1 \mathrm{a}$ and $1 \mathrm{~b}$ ) and the extinction of fear to that CS (Experiment 1b). In contrast, neither protein synthesis inhibition nor ERK/MAPK inhibition affected extinction. These results thus suggest that the MGN is indeed involved in auditory processing during extinction, but only insofar as it relays sensory information to the forebrain. Given the critical role of thalamoamygdala projections in the acquisition of auditory fear conditioning (Iwata et al., 1986; LeDoux et al., 1983, 1985, 1986), it is likely that the glutamate receptor antagonism in the MGN prevents extinction by limiting auditory transmission to the amygdala.

Not surprisingly, we found that glutamate receptor antagonism in the MGN completely eliminated the expression of fear to the auditory CS. This suppression of freezing behavior was not due to a general inability of the rats to perform the freezing response or mobilize fear responses because post-shock freezing is not affected by glutamate antagonism in the MGN (Maren et al., 2003). This confirms the essential role for excitatory synaptic transmission in the MGN in conveying auditory information to forebrain structures including the amygdala that are required for the expression of fear memory. Interestingly, the results of Experiment 1a also indicate that the expression of the freezing CR is not essential for extinction. In this experiment, glutamate receptor antagonists severely impaired the expression of fear during the extinction session, but these animals showed significant retention of extinction the following day. These data present problems for theories of extinction, which posit the formation of inhibitory associations between CSs and the resulting fear responses because our rats appeared to form these associations in the absence of a fear response (e.g., Krupa \& Thompson, 2003; Rescorla, 1993).
The ability of MGN glutamate receptor antagonists to prevent extinction learning depended on the length of the extinction session. In Experiment 1a, extinction learning was relatively unaffected by MGN glutamate receptor antagonism, but was virtually abolished in Experiment 1b. We suggest that spared extinction in Experiment 1a is due to the relatively short duration of action of the antagonists which allowed extinction trials late in the session to access forebrain circuitry. Indeed, when we cut the duration of the extinction session in half Experiment 1b), we found a profound impairment in extinction after infusion of glutamate receptor antagonists into the MGN. It might be tempting to imagine that massing stimuli during the shorter extinction session weakened extinction memory thereby making it vulnerable to the drug manipulation. However, it has been reported that massed extinction sessions actually produce more robust extinction (Cain, Blouin, \& Barad, 2003), thereby making it unlikely that the drug effect depended on memory strength. Additionally, the shift in ITI from conditioning to extinction in Experiment 1b may have fostered a discriminative relationship between CS and US pairings under long ITIs as compared to CS-no US pairings under short ITIs, rather than encouraging extinction to the CS. Again, this possibility does not seem likely insofar as shifts in ITIs between conditioning and extinction are not likely to affect extinction per se, but may serve as retrieval cues for extinction performance (Bouton, Garcia-Gutierrez, Zilski, \& Moody, 2006). Given that the ITIs were matched between the extinction and test sessions, the extinction memory would dominate performance.

Although the MGN is clearly involved in the extinction of fear to an auditory CS, it does not appear to be a locus of plasticity essential for formation of the extinction memory. For example, extinction was unaffected by infusions of the protein synthesis inhibitor anisomycin prior to extinction training. This is consistent with several reports that have failed to observe impairments in the consolidation of auditory fear conditioning after protein synthesis inhibition in MGN (Aspergis-Schoute et al., 2005; Maren et al., 2003; cf., Parsons et al., 2006). Although protein synthesis in MGN does not appear to be essential for auditory fear conditioning, there is some evidence that MEK activity in the MGN is involved (Aspergis-Schoute et al., 2005). Nonetheless, we found no evidence for impaired extinction after MEK inhibition in MGN. Together, these data suggest that MGN synaptic transmission is involved in relaying auditory information to forebrain structures involved in extinction learning.

The failure to disrupt long-term extinction memory with protein synthesis inhibition in the MGN supports the view that the amygdala is the central substrate for the formation of extinction memory. Infusions of the NMDA receptor antagonist APV into the amygdala reduce the extinction of auditory (Falls, Miserendino, \& Davis, 1992; Lin, Yeh, Lu, \& Gean, 2003) and contextual (Laurent \& Westbrook, 2009) fear and partial agonists of the NMDA receptor potentiate extinction when infused into the amygdala (Walker \& Davis, 2002; Walker, Ressler, Lu, \& Davis, 2002; Ledgerwood, Richardson, \& Cranney, 2003). Moreover, intra-amygdala infusions of anisomycin (Lin et al., 2003) or MAPK inhibitors (Lu, Walker, \& Davis, 2001; Herry, Trifilieff, Micheau, Luthi, \& Mons, 2006) block the consolidation of extinction. Interestingly, extinction also reduces GluR1 (Mao, Hsiao, \& Gean, 2006; Kim et al., 2007) and GluR2 (Kim et al., 2007) expression and MAPK phosphorylation (Lin, Lee, \& Gean, 2003; cf. Herry et al., 2006) in the amygdala. Collectively, these data support the view that the amygdala is a critical site of neuronal plasticity underlying extinction memory.

In addition to the amygdala, there is substantial evidence that the medial prefrontal cortex ( $\mathrm{MPFC}$ ) is involved in the consolidation and storage of extinction memories. For instance, lesions of the mPFC disrupt rats' ability to recall extinction from the previous day (Quirk, Russo, Barron, \& Lebron, 2000). Infusions of NMDA 
receptor antagonists into the $\mathrm{MPFC}$ immediately after extinction training block the consolidation of extinction for auditory CSs (Sotres-Bayon, Diaz-Mataix, Bush, \& LeDoux, 2009; Burgos-Robles, Vidal-Gonzalez, Santini, \& Quirk, 2007) and contexts (Laurent \& Westbrook, 2008). Additionally, infusions of anisomycin or MEK inhibitors (Hugues, Deschaux, \& Garcia, 2004) into the mPFC also retard extinction (Santini, Ge, Ren, Pena de Ortiz, \& Quirk, 2004). Taken together, there is strong evidence that both the amygdala and $\mathrm{MPFC}$ have significant roles in the formation and consolidation of extinction memories, and the MGN appears to be an essential sensory relay to these forebrain structures.

Another target of MGN output that may be involved in extinction learning is the auditory cortex. It is well known that projections between both the MGN and the auditory cortex and the amygdala are involved in auditory fear conditioning (Boatman \& Kim, 2006; Romanski \& LeDoux, 1992, 1993). Furthermore, there are reports that lesions of the auditory cortex disrupt extinction of differential heart rate conditioning (Teich et al., 1989) and conditional freezing (Song \& Kim, 2004). Additionally, lesions of the amygdala disrupt the enhancement of auditory cortical single-unit activity that normally develops during fear conditioning in intact rats (Armony, Quirk, \& LeDoux, 1998). Nonetheless, a more complete investigation of the auditory cortex during is required to understand its contribution to extinction learning.

In summary, we have found that glutamatergic transmission in the MGN is necessary for extinction of auditory fear, but that cellular cascades consequent to glutamate receptor activation are not required for the formation of extinction memories. These findings reinforce the importance of medial geniculate auditory processing as an essential step in learning processes involving auditory stimuli.

\section{References}

Armony, J. L., Quirk, G. J. \& LeDoux, J. E. (1998). Differential effects of amygdala lesions on early and late plastic components of auditory cortex spike trains during fear conditioning. Journal of Neuroscience, 18, 2592-2601.

Aspergis-Schoute, A. M., Debiec, J., Doyere, V., LeDoux, J. E., \& Schafe, G. E. (2005) Auditory fear conditioning and long-term potentiation in the lateral amygdala require ERK/MAPK kinase signaling in the auditory thalamus: A role for presynaptic plasticity in the fear system. Journal of Neuroscience, 25, 5730-5739.

Boatman, J. A., \& Kim, J. J. (2006). A thalamo-cortico-amygdala pathway mediates auditory fear conditioning in the intact brain. European Journal of Neuroscience, $24,894-900$.

Bouton, M. E. (1993). Context, time, and memory retrieval in the interference paradigms of Pavlovian learning. Psychological Bulletin, 114, 80-99.

Bouton, M. E., Garcia-Gutierrez, A., Zilski, J., \& Moody, E. W. (2006). Extinction in multiple contexts does not necessarily make extinction less vulnerable to relapse. Behaviour Research and Therapy, 44, 983-994.

Burgos-Robles, A., Vidal-Gonzalez, I., Santini, E., \& Quirk, G. J. (2007). Consolidation of fear extinction requires NMDA receptor-dependent bursting in the ventromedial prefrontal cortex. Neuron, 53, 871-880.

Cain, C. K., Blouin, A. M., \& Barad, M. (2003). Temporally massed CS presentations generate more fear extinction than spaced presentations. Journal of Experimental Psychology: Animal Behavior Processes, 29, 323-333.

Corcoran, K. A., \& Quirk, G. J. (2007). Activity in prelimbic cortex is necessary for the expression of learned, but not innate, fears. Journal of Neuroscience, 27, 840-844.

Edeline, J. M., \& Weinberger, N. M. (1992). Associative retuning in the thalamic source of input to the amygdala and auditory cortex: Receptive field plasticity in the medial division of the medial geniculate body. Behavioral Neuroscience 106, 81-105.

Falls, W. A., Miserendino, M. J. D., \& Davis, M. (1992). Extinction of fear-potentiated startle: blockade by infusion of an NMDA antagonist into the amygdala. Journal of Neuroscience, $12,854-863$.

Fanselow, M. S., \& Poulos, A. M. (2005). The neuroscience of mammalian associative learning. Annual Review of Psychology, 56, 207-234.

Heldt, S. A., \& Falls, W. A. (2006). Posttraining lesions of the auditory thalamus, but not cortex, disrupt the inhibition of fear conditioned to an auditory stimulus. Journal of Neuroscience, 23, 763-779.

Herry, C., Trifilieff, P., Micheau, J., Luthi, A., \& Mons, N. (2006). Extinction of auditory fear conditioning requires MAPK/ERK activation in the basolateral amygdala. European Journal of Neuroscience, 24, 261-269.

Hugues, S., Deschaux, O., \& Garcia, R. (2004). Postextinction infusion of a mitogenactivated protein kinase inhibitor into the medial prefrontal cortex impairs memory of the extinction of conditioned fear. Learning \& Memory, 11, 540-543.
Iwata, J., LeDoux, J. E., Meeley, M. P., Arneric, S., \& Reis, D. J. (1986). Intrinsic neurons in the amygdaloid field projected to by the medial geniculate body mediate emotional responses conditioned to acoustic stimuli. Brain Research, 383 , 195-214.

Jarrell, T. W., Gentile, C. G., McCabe, P. M., \& Schneiderman, N. (1986). The role of the medial geniculate region in differential Pavlovian conditioning of bradycardia in rabbits. Brain Research, 374, 126-136.

Ji, J., \& Maren, S. (2007). Hippocampal involvement in contextual modulation of fear extinction. Hippocampus, 17, 749-758.

Kim, J., Lee, S., Hong, I., Song, B., Son, G., Park, H., et al. (2007). Amygdala depotentiation and fear extinction. Proceedings of the National Academy of Science, 104, 20955-20960.

Krupa, D. J., \& Thompson, R. F. (2003). Inhibiting the expression of a classically conditioned behavior prevents its extinction. Journal of Neuroscience, 23, 10577-10584.

Laurent, V., \& Westbrook, R. F. (2008). Distinct contributions of the basolateral amygdala and the medial prefrontal cortex to learning and relearning extinction of context conditioned fear. Learning \& Memory, 15, 657-666.

Laurent, V., \& Westbrook, R. F. (2009). Infusion of the NMDA receptor, DL-APV, into the basolateral amygdala disrupts learning to fear a novel and a familiar context as well as relearning to fear an extinguished context. Learning E Memory, 16, 96-105.

Ledgerwood, L., Richardson, R., \& Cranney, J. (2003). Effects of D-cycloserine on extinction of conditioned freezing. Behavioral Neuroscience, 117, 341-349.

LeDoux, J. E., Iwata, J., Pearl, D., \& Reis, D. J. (1986). Disruption of auditory but not visual learning by destruction of intrinsic neurons in the rat medial geniculate body. Brain Research, 371, 395-399.

LeDoux, J. E., Ruggiero, D. A., \& Reis, D. J. (1985). Projections to the subcortical forebrain from anatomically defined regions of the medial geniculate body in the rat. Journal of Comparative Neurology, 242, 182-213.

LeDoux, J. E., Sakaguchi, A., \& Reis, D. J. (1983). Subcortical efferent projections of the medial geniculate nucleus mediate emotional responses conditioned to acoustic stimuli. Journal of Neuroscience, 4, 683-698.

Lennartz, R. C., \& Weinberger, N. M. (1992). Frequency-specific receptive field plasticity in the medial geniculate body induced by pavlovian fear conditioning is expressed in the anesthetized brain. Behavioral Neuroscience, 106, 484-497.

Lin, C., Lee, C., \& Gean, P. (2003). Involvement of a calcineurin cascade in amygdala depotentiation and quenching of fear memory. Molecular Pharmacology, 63 , 44-52.

Lin, C., Yeh, S., Lu, H., \& Gean, P. (2003). The similarities and diversities of signal pathways leading to consolidation of conditioning and consolidation of extinction of fear memory. Journal of Neuroscience, 23, 8310-8317.

Lu, K. T., Walker, D. L., \& Davis, M. (2001). Mitogen-activated protein kinase cascade in the basolateral nucleus of amygdala is involved in extinction of fearpotentiated startle. Journal of Neuroscience, 21, RC162.

Mao, S. C., Hsiao, Y. H., \& Gean, P. W. (2006). Extinction training in conjunction with a partial agonist of the glycine site on the NMDA receptor erases memory trace. Journal of Neuroscience, 26, 8892-8899.

Maren, S. (2001). Neurobiology of Pavlovian fear conditioning. Annual Review of Psychology, 24, 897-931.

Maren, S., Ferrario, C. R., Corcoran, K. A., Desmond, T. J., \& Frey, K. A. (2003). Protein synthesis in the amygdala, but not the auditory thalamus, is required for consolidation of Pavlovian fear conditioning in rats. European Journal of Neuroscience, 18, 3080-3088.

Maren, S., \& Quirk, G. J. (2004). Neuronal signalling of fear memory. Nature Reviews Neuroscience, 5, 844-852.

McCabe, P. M., McEchron, M. D., Green, E. J., \& Schneiderman, N. (1993). Electrolytic and ibotenic acid lesions of the medial subnucleus of the medial geniculate prevent the acquisition of classically conditioned heart rate to a single acoustic stimulus in rabbits. Brain Research, 619, 291-298.

McEchron, M. D., McCabe, P. M., Green, E. J., Llabre, M. M., \& Schneiderman, N. (1995). Simultaneous single unit recording in the medial nucleus of the medial geniculate nucleus and amygdaloid central nucleus throughout habituation, acquisition, and extinction of the rabbit's classically conditioned heart rate. Brain Research, 682, 157-166.

Myers, K. M., \& Davis, M. (2002). Behavioral and neural analysis of extinction. Neuron, 36, 567-584.

Parsons, R. G., Riedner, B. A., Gafford, G. M., \& Helmstetter, F. J. (2006). The formation of auditory fear memory requires the synthesis of protein and mRNA in the auditory thalamus. Neuroscience, 141, 1163-1170.

Quirk, G. J., \& Mueller, D. (2008). Neural mechanisms of extinction learning and retrieval. Neuropsychopharmacology, 33, 56-72.

Quirk, G. J., Russo, G. K., Barron, J. L., \& Lebron, K. (2000). The role of ventromedial prefrontal cortex in the recovery of extinguished fear. Journal of Neuroscience, $20,6225-6231$

Rescorla, R. A. (1993). Inhibitory associations between S and R in extinction. Animal Learning E' Behavior, 21, 327-336.

Romanski, L. M., \& LeDoux, J. E. (1992). Equipotentiality of thalamo-amygdala and thalamo-cortico-amygdala circuits in auditory fear conditioning. Journal of Neuroscience, 12, 4501-4509.

Romanski, L. M., \& LeDoux, J. E. (1993). Organization of rodent auditory cortex: Anterograde transport of PHA-L from MGv to temporal neocortex. Cerebral Cortex, 3, 499-514.

Santini, E., Ge, H., Ren, K., Pena de Ortiz, S., \& Quirk, G. J. (2004). Consolidation of fear extinction requires protein synthesis in the medial prefrontal cortex. Journal of Neuroscience, 24, 5704-5710. 
Schafe, G. E., \& LeDoux, J. E. (2000). Memory consolidation of auditory Pavlovian fear conditioning requires protein synthesis and protein kinase $\mathrm{A}$ in the amygdala. Journal of Neuroscience, 20, 1-5.

Schauz, C., \& Koch, M. (2000). Blockade of NMDA receptors in the amygdala prevents latent inhibition of fear-conditioning. Learning \& Memory, 7, 393-399.

Song, E., \& Kim, J. J. (2004). Effects of auditory cortex lesions of acquisition and extinction of fear conditioning to two different auditory stimuli in rats. Program No. 773.16. 2004 Abstract viewer/itinerary planner. Washington, DC: Society for Neuroscience.

Sotres-Bayon, F., Diaz-Mataix, L., Bush, D. E. A., \& LeDoux, J. E. (2009). Dissociable roles for the ventromedial prefrontal cortex and amygdala in fear extinction: NR2B contribution. Cerebral Cortex, 19, 474-482.

Swanson, L. W. (2004). Brain maps: Structure of the rat brain (3rd ed). San Diego, California: Elsevier Academic Press.

Teich, A. H., McCabe, P. M., Gentile, C. C., Schneiderman, L. S., Winters, R. W. Liskowsky, D. R., et al. (1989). Auditory cortex lesions prevent the extinction of Pavlovian differential heart rate conditioning to tonal stimuli in rabbits. Brain Research, 480, 210-218.
Walker, D. L., \& Davis, M. (1997). Double dissociation between the involvement of the bed nucleus of the stria terminalis and the central nucleus of the amygdala in startle increases produced by conditioned versus unconditioned fear. Journal of Neuroscience, 17, 9375-9383.

Walker, D. L., \& Davis, M. (2002). The role of amygdala glutamate receptors in fear learning, fear-potentiated startle, and extinction. Pharmacology, Biochemistry and Behavior, 71, 379-392.

Walker, D. L., Ressler, K. J., Lu, K. T., \& Davis, M. (2002). Facilitation of conditioned fear extinction by systemic administration or intra-amygdala infusions of Dcycloserine as assessed with fear-potentiated startle in rats. Journal of Neuroscience, 22, 2342-2351.

Webber, T. J., Green, E. J., Winters, R. W., Schneiderman, N., \& McCabe, P. M. (1997). Contribution of NMDA and non-NMDA receptors to synaptic transmission from the brachium of the inferior colliculus to the medial subdivision of the medial geniculate nucleus in the rabbit. Experimental Brain Research, 124, 295-303.

Zhang, W. N., Bast, T., \& Feldon, J. (2001). The ventral hippocampus and fear conditioning in rats: Different anterograde amnesias of fear after infusion of $\mathrm{N}$ methyl-D-aspartate of its noncompetitive antagonist MK-801 into the ventral hippocampus. Behavioral Brain Research, 126, 159-174. 